\title{
Giant Ovarian Tumour
}

\begin{abstract}
CEZAR LAURENTIU TOMESCU1,3, GABRIELA STANCIU2*, TEODOR STEFAN NITU33, MADALINA BOSOTEANU ${ }^{3}$, RODICA SIRBU ${ }^{4}$, DRAGOS MARIAN BREZEANU', ANETA TOMESC $U^{1,3 *}$

'Ovidius University of Constanta, Faculty of Medicine, 1 Universitatii Alley, 900470, Constanta, Romania

2Ovidius University of Constanta, Department of Chemistry and Chemical Engineering, 1 Universitatii Alley, 900470, Constanta, Romania

${ }^{3}$ Second Department of Obstetrics and Gynecology, County Clinical Emergency Hospital Sf. Apostol Andrei, 145 Tomis Blvd., 900591, Constanta, Romania

Abdominal-pelvic masses are an important part of the female pelvic pathology. They can belong either to the uterus, ovaries or the fallopian tubes. The main symptoms are represented by abdominal and pelvic pain, and in certain cases significant abdominal distension. These can sometimes be accompanied by secondary symptoms, according to the nearby organs involved. Herein, we present the case of a 42-yearold patient with an impressive ovarian tumour mass (50kg).
\end{abstract}

Keywords: mucinous ovarian tumour, ovarian cancer, borderline tumour, inhibin, CA-125, CA 19-9

Ovarian tumours represent an increasingly more frequent pathology in recent years. Referring strictly to malignant ovarian masses, these have an incidence of approximately 239.000 cases per year worldwide, accounting for 152.000 deaths annually [1].

In the US, approximately 21.290 new cases are registered each year, with a yearly death rate of 14.180 [2].

By contrast, China registers approximately 52.100 new cases each year, 22.500 of them leading to death [3].

A histological variant is represented by the mucinous ovarian tumour, which can either be benign, borderline or malignant [4].

Borderline tumours represent approximately $10-20 \%$ of all ovarian tumours [5].

Until 2004, mucinous ovarian tumours were considered as belonging to the epithelial ovarian tumours group. Nowadays, they are considered a separate group and are simply called mucinous ovarian tumours [6,7].

Borderline tumours have the highest incidence of all mucinous tumours, representing up to $67 \%$ of this type of tumour[8].

\section{Experimental part}

Case presentation

42-year-old patient D.F presents to the Emergency Department of the County Clinical Emergency Hospital Sf. Ap. Andrei Constanta on the 20 $0^{\text {th }}$ of April 2017, complaining of intense abdominal and pelvic pain for approximately 24 hours, as well as progressive enlargement of the abdomen over the previous year.

From the patient's medical history, we note one pregnancy delivered via Caesarean-section in 1994 and a miscarriage at 7 weeks' gestational age. Patient denies any other health issues, alcohol consumption or cigarette smoking.

Clinical examination reveals enlarged, tense abdomen, painful upon palpation. Weighing of the patient reveals a weight of $105 \mathrm{~kg}$. Pelvic and speculum examination do not reveal any pathological abnormalities.

An abdominal ultrasound is performed on the $20^{\text {th }}$ of April 2017, which reveals a giant tumour mass occupying the entire abdomen with dimensions of $50 / 70 / 60 \mathrm{~cm}$, stretching from the xiphoid process to the pubic symphysis and both flanks of the abdomen. An inhomogeneous aspect of the

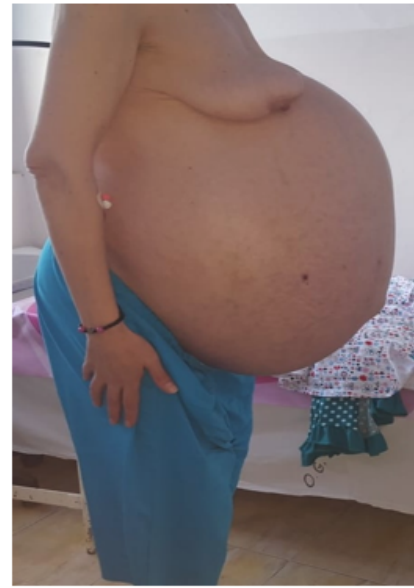

Fig. 1. Preoperative aspect

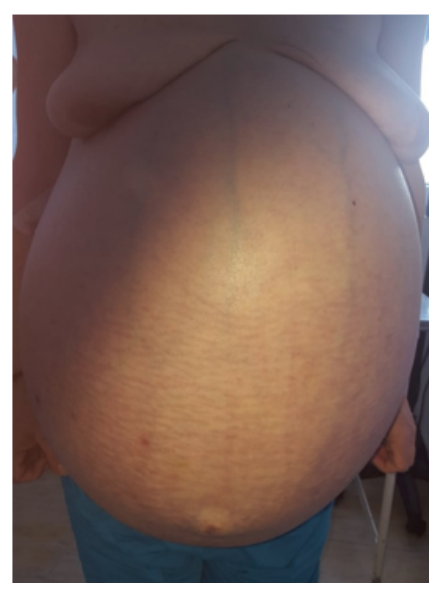

Fig. 2. Preoperative aspect mass is observed, with a predominance of hyperechoic content

Based on the clinical examination, laboratory testing and imagistic results it is decided to admit the patient to the $2^{\text {nd }}$ Department of Obstetrics and Gynaecology with the following diagnosis: Voluminous abdominal-pelvic tumoural mass.

A CT scan is also performed in the same day, revealing an abdominal and pelvic cystic mass measuring 35/41/52 $\mathrm{cm}$, apparently attached to the broad ligament of the uterus, which compresses the intestinal loops, the pancreas, the splenic and superior mesenteric veins and the right ureter, aspect compatible with an ovarian serous cystadenoma.

In what regards laboratory testing, we note a ROMA score of $22.47 \%$, compatible with an increased risk for an epithelial ovarian cancer.

Preoperative laboratory testing showed mild anaemia $(\mathrm{Hb}=10.5 \mathrm{~g} / \mathrm{dl})$, the remainder of tests being within normal limits.

\section{Results and discussions}

Surgical interventions are performed by a mixed gynaecology-general surgery team $25^{\text {th }}$ of April 2017. Upon opening of the peritoneal cavity, a giant white pearly tumoural mass, with thin walls and intact capsule, of approximately $60 / 40 / 45 \mathrm{~cm}$ is noted. The capsule is incised

\footnotetext{
* email: GSTANCIU@univ-ovidius.ro, Phone: +40241600488; tomescu.aneta@gmail.com, Phone: +40 722331961
}

All authors are considered main authors with equal contributions 


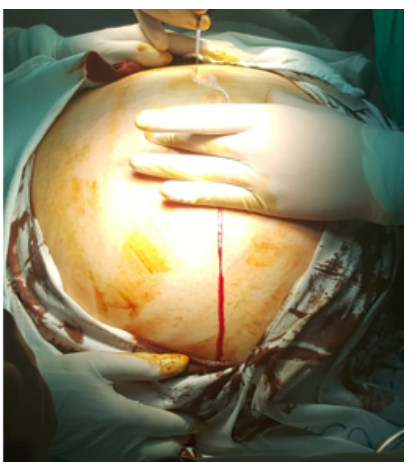

Fig. 3. Skin level incision

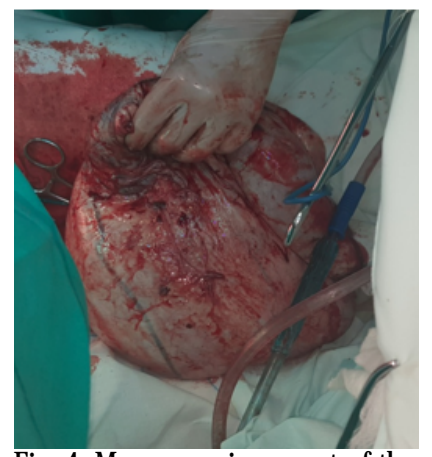

Fig. 4. Macroscopic aspect of the tumour after evacuation of $40 \mathrm{l}$ of serous fluid and 40 litres of liquid are aspirated, of which a sample is preserved for cytological examination. Left adnexectomy and right sal pingectomy is performed. Samples are sent to intraoperative frozen section examination which established the diagnosis of mucinous proliferative ovarian tumour. The final diagnosis will be certified by paraffin histopathology examination.

\section{Intraoperative frozen section examination}

Cystic transformation of the ovary with a diameter of 40 centimetres, with microscopic lesions compatible with the diagnosis of borderline mucinous cystadenoma of the ovary - atypical cystic mucinous tumour.

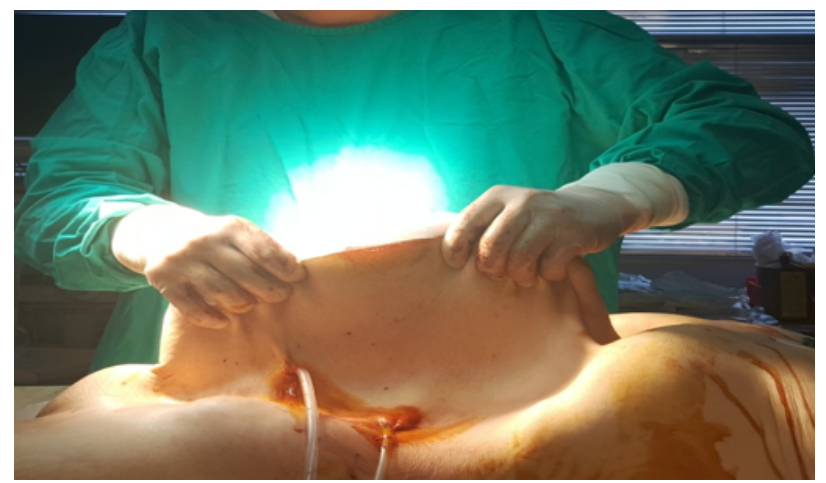

Fig. 5. Postoperative aspect - excess skin tissue

During surgery, the patient received 2 units of red cells and fresh frozen plasma. Postoperative evolution of the patient was favourable and she was discharged on the $3^{\text {rd }}$ of May 2017. Post surgical weight of the patients was 55 $\mathrm{kg}$, the patient having lost a total of $50 \mathrm{~kg}$ as a result of surgery.

Discharge laboratory testing is within normal limits, with the exception of a mild hypochromic microcytic anaemia, for which she was recommended treatment with iron supplements.

Final histopathological examination and immunohistochemistry

Final histopathological examination

Macroscopic description

Open and drained cystic mass with a diameter of 40 centimetres, wall thickness of $0.3 \mathrm{~cm}$, with a smooth, white greyish external surface. The internal surface presents 3 exophytic lesions, of $6 / 3.5 / 2.5 \mathrm{~cm}, 4.5 / 3 / 1 \mathrm{~cm}$ and $3 / 2.5 /$ $1.5 \mathrm{~cm}$ respectively, grey pink in colour, with haemorrhagic areas, of slightly decreased consistency, friable.

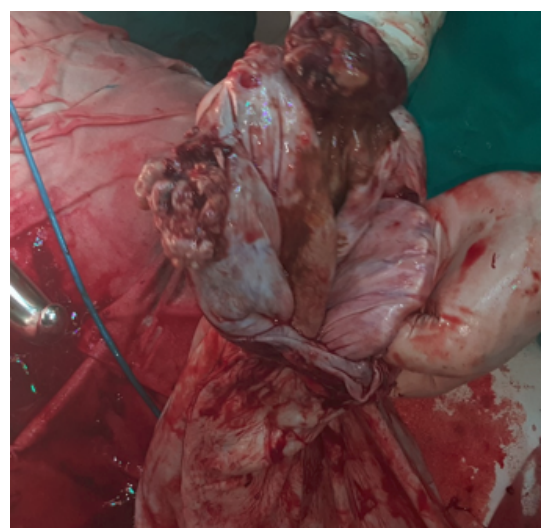

Fig. 6. Intraoperative macroscopic aspect of the intracystic exophytic lesions

\section{Microscopic description}

Borderline mucinous cystadenoma of the ovary (figures 7,8) which presents, at the stromal level, foci comprising glandular structures with architectural complexity and expansile pattern, lined by multistratified epithelial cells with moderate cytonuclear atypia, mitotic activity and minimal/absent stromal interposition (figures 9, 10, 11); the diameter of the described lesional areas varies between 3-5 $\mathrm{mm}$. The adjacent stroma reveals desmoplastic appearance (figure 12). Lympho-vascular and perineural invasion were not identified. The lesions are accompanied by areas of hemorrhagic necrosis, vascular thrombosis and chronic inflammatory infiltrate; the outer surface of the ovary is not affected.

All of the above-mentioned histological elements are compatible with the diagnosis of atypical proliferative mucinous tumour of the ovary, gastro-intestinal type, with microinvasion - expansile pattern.

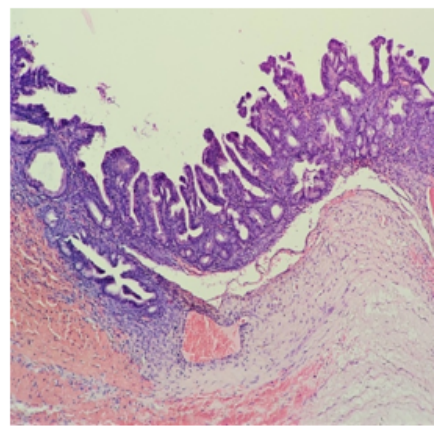

Fig 7. Borderline mucinous ovary cystadenoma Haematoxylin Eosin stain X100

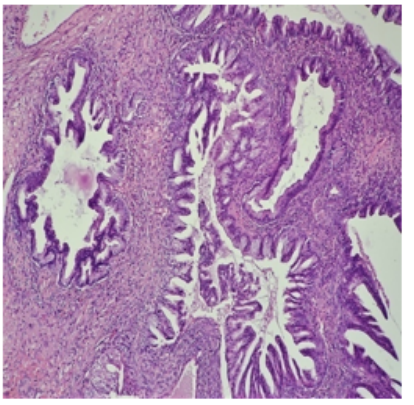

Fig 8. Borderline mucinous ovary cystadenoma Haematoxylin Eosin stain X200

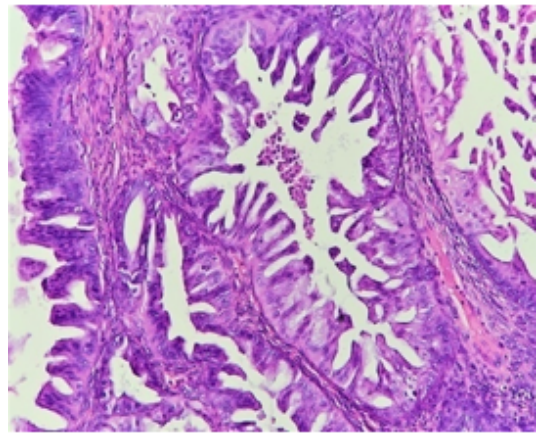

Fig 9. Microinvasion foci Haematoxylin Eosin stain 200X 


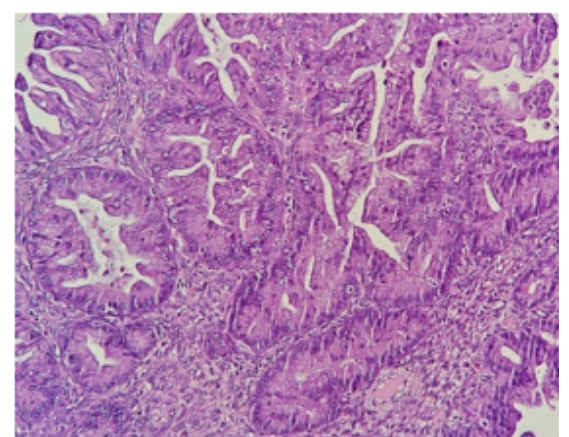

Fig 10. Microinvasion foci Haematoxylin Eosin stain 100X

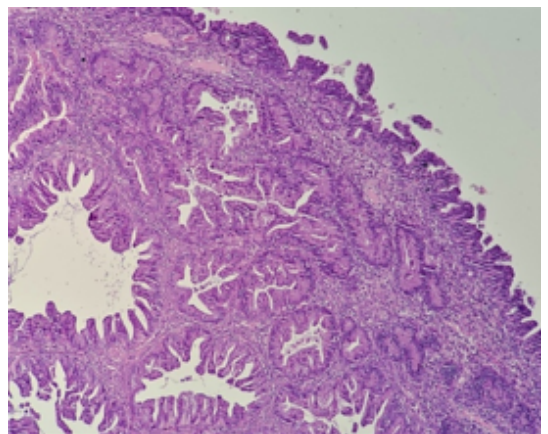

Fig 11. Microinvasion foci Haematoxylin Eosin stain $100 \mathrm{X}$

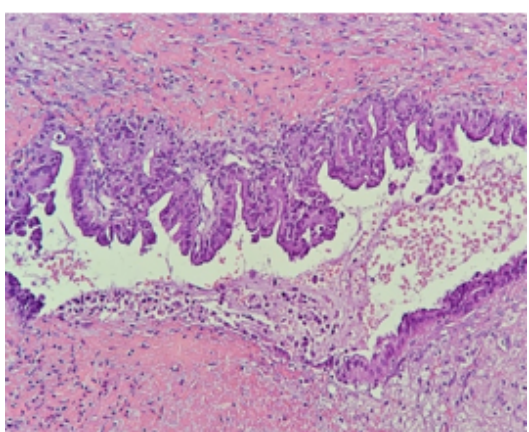

Fig 12. Microinvasion foci Haematoxylin Eosin stain 200X

\section{Immunohistochemistry}

Ovary fragments showing tumoral proliferation compatible with borderline mucinous tumour/atypical proliferative mucinous tumour with microinvasion, accompanied by haemorrhagic and necrotic areas.

Table 1

IMMUNOHISTOCHEMISTRY

\begin{tabular}{|c|c|}
\hline CK7 & + diffusely in tumoral cells \\
\hline CK20 & + diffusely in tumoral cells \\
\hline ER & - in tumoral cells and + in stroma \\
\hline PGR & - in tumoral cells and + in stroma \\
\hline PAX8 & + focally in tumoral cells \\
\hline p53 & + in $50 \%$ of cells \\
\hline Ki67 & + in $60 \%$ of cells \\
\hline
\end{tabular}

Immunohistochemistry, correlated with histopathological examination and anatomical and clinical data support the diagnosis of borderline mucinous ovarian tumour/atypical proliferative mucinous tumour of the ovary, with microinvasion.

\section{Postoperative follow-up}

Since the surgical intervention and up to the present moment, the patient is followed-up every 6 months by the oncologist, which entails the dosing of CA-125 and inhibin as well as abdominal and pelvic CT scans. The last two native and contrast CT scans performed on the $17^{\text {th }}$ of January 2019 and $18^{\text {th }}$ of July 2019 respectively, show no signs of local or regional relapse.

The main symptom of mucinous ovarian tumours is represented by pain. This is present in up to $42.7 \%$ of patients [9].

In what regards laboratory testing, CA-125 alone is less useful in discovering mucinous ovarian tumours. In order to diagnose this type of tumour, CA19-9 is more useful [10]. CA-125 has a sensitivity rate of $51.9 \%$ for the diagnosis of mucinous tumours and up to $68.2 \%$ in epithelial nonmucinous tumours. CA19-9 has a specificity rate of $51.5 \%$ in serous tumour and up to $44.7 \%$ in mucinous tumours [11].

In the postoperative period, the combined dosing of CA125 and CA19-9 has shown a much higher sensitivity in long term follow-up compared to CA-125 alone [10].

The association between CA-125 and HE4, known as the ROMA score has a higher sensitivity compared to CA125 [12]. A 2016 study performed by Su Wei has shown a much higher sensitivity of the ROMA score in detecting ovarian tumours compared to CA-125 alone [13].
A high specificity in the postoperative follow-up of a patient diagnosed with ovarian mucinous tumour is represented by the association between CA-125 and inhibin. Inhibin is a hormone involved in ovarian fertility, which decreases significantly in menopause. An increase in inhibin during menopause is associated with ovarian mucinous tumours [14].

In order to support the diagnosis, imagistic investigation, such as abdominal or transvaginal ultrasound can be performed. Ultrasound examination can attest, according to the characteristics of the tumoural mass, the benign or malignant features of the mass [15].

In ovarian dysgerminoma, which is a germ cell tumour, the prognosis is favourable, even without radical surgery. [16]

Investigations of a higher reliability, such as CT scans or MRI can be used both before surgery and during postoperative follow-up. MRI examination can assess the starting point of the tumoural mass and can aid in its morphologic characterization, thus influencing therapeutic approach [17].

\section{Conclusions}

The particularities of the presented case rely in the size and weight of the tumour, with the patient having lost $50 \mathrm{~kg}$ after the surgical intervention.

Postoperative evolution was favourable and follow-up is performed by a mixed gynaecologist-oncologist team every 6 months through the dosing of inhibin and CA-125, transvaginal ultrasound examination and abdominal-pelvic CT scan, which have, thus far, shown no sign of relapse.

\section{References}

1. REID, B.M., PERMUTH, J.B., SELLERS, T.A., Cancer Biol Med., 14, no. 1, 2017, p. 9.

2. American Cancer Society. Cancer Facts \&amp; Figures 2015. Atlanta: American Cancer Society, 2015.

3. CHEN, W.Q., ZHENG, R.S., BAADE P.D., ZHANG, S.W., ZENG H.M., BRAY F., CA Cancer J Clin., 66, 2016, p. 115.

4. BROWN, J., MICHAEL FRUMOVITZ,M., Curr. Oncol. Rep., 16, no. 6, 2014, p. 389.

5. SUH-BURGMANN, E., Gynecol Oncol., 103, 2006, p. 841.

6. FRUMOVITZ, M., SCHMELER, K.M., MALPICA, A., SOOD, A.K., GERSHENSON, D.M., Gynecol Oncol., 117, 2010, p. 491.

7. HESS, V., A'HERN, R., NASIRI, N., J. Clin. Oncol., 22, 2004, p. 1040. 8. SHAPPELL, H.W., RIOPEL, M.A., SMITH SEHDEV, A.E., RONNETT, B.M., KURMAN, R.J., Am. J. Surg. Pathol., 26, 2002, p. 1529.

9.COMERT, D.K., ÜREYEN, I., KARALOK, A., TASCI, T., TURKMEN, O., ÖCALAN, R., TURAN, T., TULUNAY, G., J. Turk. Ger. Gynecol. Assoc., 17, no. 2, 2016, p. 96.

10. DONG, L., CUI, H., LI, X.P., SUN, L.F., CHANG, X.H., LIANG, X.D., ZHU, H.L, Zhonghua Fu Chan Ke Za Zhi., 43, no. 1, 2008, p. 5. 11. TAMAKOSHI K, KIKKAWA F, SHIBATA K, TOMODA K, OBATA $\mathrm{NH}$, WAKAHARA F, TOKUHASHIY, ISHIKAWA H, KAWAI M, TOMODA Y, Gynecol Oncol. 1996 J ul;62(1):67-72; 
12. KARLSEN, M.A., SANDHU, N., HOGDALL, C., CHRISTENSEN, I.J., NEDERGAARD, L., LUNDVALL, L., ENGELHOLM, S.A., PEDERSEN, A.T., HARTWELL, D., LYDOLPH, M., Gynecol Oncol., 127, 2012, p. 379.

13. WEI, S., LI, H., ZHANG, B., Biomed Rep., 5, no. 1, 2016, p. 41.

14. ROBERTSON, D.M., OEHLER, M.K., Womens Health (Lond)., 1, no. 1, 2015, p. 51.
15. SAYASNEH, A., EKECHI, C., FERRARA, L., KAIJ SER, J., STALDER, C., SUR, S., TIMMERMAN, D., BOURNE, T., Int. J. Oncol., 46, no. 2, 2015, p. 445.

16. TOMESCU, A., MOCANU, L., BREZEANU, D., STANCIU, G., SIRBU, R., TOMESCU, C., Rev. Chim. (Bucharest), 70, no. 5, , 2019, p. 1731. 17. FOTI, P.V., ATTINA, G., SPADOLA, S., CALTABIANO, R., FARINA, R., PALMUCCI, S., ZARBO, G., ZARBO, R., D'ARRIGO, M., MILONE, P., ETTORRE, C.E., Insights Imaging., 7, no. 1, 2016, p. 21.

Manuscript received: 4.11 .2019 